\title{
Facilitation of free recall by categorical blocking depends on stimulus type
}

\author{
EUGENE S. GOLLIN and MATTHEW J. SHARPS \\ University of Colorado, Boulder, Colorado
}

\begin{abstract}
Items that are blocked by category are typically more memorable than unblocked items. We examined the blocking effect with different types of stimuli. In Experiment 1, subjects memorized either actual objects or the printed names of those objects. Free recall was enhanced significantly by blocking only in the printed name condition. In Experiment 2, it was demonstrated that these relationships occurred whether or not verbal labels are supplied for the stimulus items. The difference in the impact of blocking on free recall was hypothesized to reflect differences in the visual detail that characterized the stimulus items in the object and printed name conditions. To test this hypothesis, Experiment 3 was conducted, using four sets of stimulus items graded in visual detail. These were a set of objects, photographs of the objects, line drawings of the objects, and printed names of the objects. The visual detail hypothesis was supported.
\end{abstract}

Conditions at encoding that allow items to be cognitively interrelated enhance recall (see Tversky, 1973). To block stimulus items according to membership in common categories facilitates cognitive interrelations and has the expected enhancing effect on memory (see Cofer, Bruce, \& Reicher, 1966; Cole, Frankel, \& Sharp, 1971; Moely \& Shapiro, 1971).

Likewise, elaborated or detailed stimuli have been found to enhance visual memory (Nelson, Metzler, \& Reed, 1974; Park, Puglisi, \& Smith, 1986; Spoehr \& Lehmkule, 1982; Weber, Brown, \& Weldon, 1978). Ease of recall is related to the amount of elaboration or visual detail in the stimulus materials (see Bevan \& Steger, 1971; Haber \& Erdelyi, 1967; Kossuth, Carroll, \& Rogers, 1971; Nelson et al., 1974; Paivio, 1969; Scott, 1967). Actual objects are remembered better than are their pictures, and pictures are, in general, recalled better than words (Spoehr \& Lehmkule, 1982).

In investigations of the effect of blocking, the stimulus materials have generally been line drawings or printed words, that is, stimuli of relatively low visual detail. Because objects are recalled easily and are high in visual detail, we hypothesized that they would be less affected by blocking than would low-detail printed words. Pilot studies indicated that only $60-70 \%$ of the objects used in the experiments reported below were remembered in free recall paradigms. This provided assurance that any failure to find blocking effects for the objects would not be due to a ceiling effect.

This research was supported by Grant IRO1 AG05952-01 from the National Institute on Aging. Correspondence may be addressed to Eugene S. Gollin, Campus Box 345, University of Colorado, Boulder, CO 80309 .

\section{EXPERIMENT 1}

In Experiment 1, free recall for objects and their printed names was tested in blocked and unblocked conditions to determine whether or not the blocking effect was dependent on stimulus type. The effect on free recall of prior knoweldge of the stimulus categories was also tested, since the provision of information about the categories of to-be-remembered items has been shown to aid memory in a variety of experimental contexts (e.g., Buschke \& Lazar, 1973; Hultsch, 1969; Strand, 1975).

\section{Method}

Subjects. One hundred and twenty adults between the ages of 17 and 30 years were recruited from the introductory psychology classes at the University of Colorado, Boulder. By means of the Snellen eye test, all subjects were ascertained to possess visual acuity of 20/40 or better, corrected or uncorrected.

Materials. Four sets of 10 small objects each were used as stimuli. Each set consisted of one type of object: animals, vehicles, kitchen things, or medical things. The objects ranged in size from 1 to 3 in. in overall dimensions. All the objects were ascertained to be readily identifiable at a distance of $2 \mathrm{~m}$ by individuals with visual acuity not less than $20 / 40$. Four sets of $12.7 \times 17.78 \mathrm{~cm}$ cards ( 10 cards per set) were constructed. The names of the items were printed on the cards, one per card, in letters approximating Snellen Line 4 in dimension (approximately $2.3 \mathrm{~cm}$ high).

Design. The experiment was a $2 \times 2 \times 2$ between-subjects design The independent variables comprised (1) stimulus type (either objects or their printed names); (2) information (either information about the four item categories, or no information about category); and (3) presentation type (items either blocked in their categories or unblocked).

Procedure. The subjects were seated in groups of 4 to 8 , in a semicircle $1.5 \mathrm{~m}$ from the experimenter, who stood at a podium. Letters from Snellen Line 7, much smaller than any of the stimulus items to be presented, were shown to the subjects by the experimenter, and the subjects were asked to identify them in writing. All the subjects correctly identified these letters and their order. 
The subjects were informed that they would see some objects or printed words (depending on condition), and that they were to remember what these were. The subjects in the informed condition were told prior to presentation that the items belonged to one of four categories-animals, vehicles, kitchen things, or medical things - and that they could use the categories to help their memory. The subjects in the uninformed condition were not given this information. The items were presented either by category, blocked in four groups of 10 , or, in the unblocked condition, in one of four orders generated with the stipulation that no more than 2 items from any category could occur sequentially in the order of presentation, and that each category would be represented equally often in each half of the presented lists. The subjects were assigned randomly to the conditions of the experiment.

After instructing the subjects, the experimenter presented the printed name cards or the objects. These were taken singly from a covered box, held up at a distance of $1.5 \mathrm{~m}$ from the subjects for a period of $5 \mathrm{sec}$ each, and placed back in the box. Each stimulus item was named by the experimenter as it was presented, in order to reduce the possibility of idiosyncratic naming intrusions. Three seconds elapsed between presentations of the successive items. At the conclusion of the presentation of all 40 items, the subjects engaged in an interpolated arithmetic task for $2 \mathrm{~min}$, in order to prevent rehearsal. At the end of this period, the subjects were asked to write the names of all the items they remembered.

Scoring. A simple count of the number of correct responses constituted the free recall score. Intrusion errors, falsely recalled items that were not in the stimulus set, were counted and recorded. Intrusions were so few in number (constituting less than $3 \%$ of total responses) that they are not reported in this or the following experiments.

Clustering of items at recall was measured by means of the Adjusted Ratio of Clustering (ARC) score (Roenker, Thompson, \& Brown, 1971 ). The ARC score posits chance clustering at 0 and perfect clustering at 1 . The ARC score is calculated as

$$
\mathrm{ARC}=[R-E(R)] /[\max R-E(R)],
$$

" where $R$ is the total number of observed category repetitions, $\max R$ is the maximum possible number of category repetitions, and $E(R)$ is the expected (chance) number of category repetitions" (Roenker et al., 1971).

\section{Results}

Free recall score. The results of Experiment 1 are shown in Table 1 . The effect of stimulus type was significant $\left[F(1,112)=22.72, p<.001, \omega^{2}=.119\right]$; the objects were significantly more memorable than their printed names. The effect of information was also significant $\left[F(1,112)=3.88, p=.05, \omega^{2}=.016\right]$. The effect size was small, but the subjects informed of the categorical nature of the stimuli exhibited significantly higher free recall. Blocked stimuli were significantly more memorable overall than unblocked stimuli $[F(1,112)=$ $\left.34.91, p<.001, \omega^{2}=.186\right]$. The interaction of blocking and stimulus type was also significant $[F(1,112)=$ $\left.5.40, p=.02, \omega^{2}=.024\right]$. Tukey Honestly Significant Difference analysis $(p<.05)$ demonstrated that although there was a significant effect of blocking when the stimuli were printed names, there was no significant effect of blocking on free recall when the items employed were actual objects (see Table 1).

Because a significant effect of blocking was obtained for printed names, as had occurred in previous studies,
Table 1

Mean Numbers of Items Recalled and Mean ARC Scores, with Standard Deviations, Experiment 1

\begin{tabular}{|c|c|c|c|c|}
\hline & \multicolumn{2}{|c|}{ Recall Score } & \multicolumn{2}{|c|}{ ARC Score } \\
\hline & $M$ & $S D$ & $M$ & $S D$ \\
\hline \multicolumn{5}{|c|}{ Uninformed Condition } \\
\hline \multicolumn{5}{|l|}{ Objects } \\
\hline Blocked & 27.20 & 4.52 & .84 & .19 \\
\hline Unblocked & 24.00 & 5.11 & .52 & .38 \\
\hline \multicolumn{5}{|l|}{ Printed Names } \\
\hline Blocked & 26.80 & 5.14 & .75 & .23 \\
\hline \multirow[t]{2}{*}{ Unblocked } & 18.93 & 4.13 & .49 & .42 \\
\hline & \multicolumn{4}{|c|}{ Informed Condition } \\
\hline \multicolumn{5}{|l|}{ Objects } \\
\hline Blocked & 30.00 & 3.63 & .94 & .12 \\
\hline Unblocked & 26.93 & 3.69 & .77 & .30 \\
\hline \multicolumn{5}{|l|}{ Printed Names } \\
\hline Blocked & 26.47 & 5.10 & .87 & .18 \\
\hline Unblocked & 20.40 & 5.38 & .71 & .40 \\
\hline
\end{tabular}

the power of the experimental design was deemed sufficient to detect an effect of comparable magnitude for objects, if one did exist. Further computations showed that the power to detect an effect of half the observed magnitude was at least .77. However, smaller effects of blocking could have gone undetected by the statistical test.

No other two- or three-way interactions were significant. The four orders employed in the unblocked condition produced results that did not differ from one another statistically.

ARC score. The effect of blocking on response clustering was significant $F(1,112)=17.54, p<.001, \omega^{2}=$ .12 ]; in recall, blocked stimuli were clustered more than unblocked items. The effect of information was also significant $\left[F(1,112)=10.10, p=.002, \omega^{2}=.06\right]$; the subjects informed of the categories to which items belonged tended to cluster more than those who were not so informed. No other effects or interactions were significant (see Table 1).

\section{Discussion}

The finding that objects were more memorable than their printed names is consistent with the prior literature on recall (e.g. Bevan \& Steger, 1971 ). The finding that the informed condition produced recall superior to that of the uninformed condition is also readily understandable: the informed subjects were in a position to organize their memory by category from the beginning of the task, whereas the uninformed subjects lacked this mnemonic advantage.

There was a statistically significant interactive effect of blocking and stimulus type on free recall. A significant blocking effect was observed in the printed name condition, but no such effect was found in the object condition. This finding is consistent with the hypothesis that the blocking effect is dependent on the type of stimuli employed. Visually detailed objects are sufficiently memora- 
ble for blocking to impart little or no further mnemonic advantage to them. Printed words, by contrast, contain less visual detail and associated memorability, and they are therefore susceptible to the mnemonic advantage afforded by the blocking arrangement.

Blocking and information about category were associated with greater clustering of recalled responses (ARC scores). It is relatively easy to understand how clustered (i.e., blocked) input could lead to clustered responses at recall. The same is true for information about the categorical memberships of the stimulus items; the subjects provided with this knowledge, compared to those who did not have the information, were in a better position to maximize their recall through an internal sorting of items into their appropriate categories in memory.

Although a significant interactive effect of blocking and stimulus type was observed on free recall scores, no such effect was observed on ARC scores. Significant blocking effects were observed on the clustering of both objects and printed names, but significant blocking effects were observed on the free recall of printed names only, not of objects. Within this study, the degree of clustering (the ARC score) did not directly predict the level of recall (the free recall score). This indicates that there was some functional independence among the clustering, recall, and stimulus conditions. Conditions that are conducive to clustering may not be conducive to better recall, and the clustering that occurs under such conditions may not act to enhance recall.

\section{EXPERIMENT 2}

Each item, whether an object or a printed name, was named when it was presented in Experiment 1. The statement of names in the printed name condition thus provided redundant information. But when names were used with the actual objects, the subjects were supplied with nonredundant information. Although there was a significant blocking effect with printed names, there was only a nonsignificant tendency toward a blocking effect with objects. Experiment 2 was designed to examine the possibility of an interaction between naming and stimulus type.

\section{Method}

Forty subjects (aged 17-23 years, with a minimum visual acuity of 20/40) were recruited from the intraductory psychology classes at the University of Colorado; they were assigned randomly to the four cells of a $2 \times 2$ design. The independent variables included blocking (stimulus items either blocked by category or unblocked) and stimulus type (either objects or their printed names). The procedure was the same as in Experiment 1, with the exception that this time, verbal labels and information about category were not provided.

\section{Results and Discussion}

The results of Experiment 2 replicated those of Experiment 1 (see Table 2). The effects of blocking and of stimulus type were significant on free recall $[F(1,36)=$ $5.99, p=.019, \omega^{2}=.08$, and $F(1,36)=9.14, p=$
Table 2

Mean Numbers of Items Recalled and Mean ARC Scores, with Standard Deviations, Experiment 2

\begin{tabular}{|c|c|c|c|c|}
\hline & \multicolumn{2}{|c|}{ Recall Score } & \multicolumn{2}{|c|}{ ARC Score } \\
\hline & $M$ & $S D$ & $M$ & $S D$ \\
\hline \multicolumn{5}{|l|}{ Objects } \\
\hline Blocked & 26.40 & 4.38 & .65 & .25 \\
\hline Unblocked & 26.70 & 2.27 & .55 & .34 \\
\hline \multicolumn{5}{|l|}{ Printed Names } \\
\hline Blocked & 27.50 & 4.47 & .82 & .26 \\
\hline Unblocked & 18.80 & 5.73 & .43 & .37 \\
\hline
\end{tabular}

$\left..005, \omega^{2}=.13\right]$, indicating that blocked stimuli were remembered better than unblocked items, and that visually detailed objects were remembered better than nondetailed printed names. The interaction of blocking and stimulus type was also significant $[F(1,36)=10.49, p=.003$, $\left.\omega^{2}=.15\right]$; recall performance with stimulus objects was not significantly influenced by blocking, whereas blocked printed names were recalled better than were unblocked names. Tukey HSD analysis $(p<.05)$ yielded virtually the same results as in Experiment 1. However, in Experiment 1 , there was a slight but nonsignificant tendency for the blocked presentation of objects to produce better recall performance than the unblocked presentation did. There was no such tendency in Experiment 2. An analysis of variance across the relevant experimental conditions of Experiments 1 and 2 confirmed that there was no significant interaction. The effect of blocking on the ARC score was significant $\left[F(1,36)=5.87, p<.021, \omega^{2}=.11\right]$. No other effects or interactions were significant.

The replication of the results of Experiment 1 in the absence of verbal labeling indicated that the verbal naming of stimulus items did not influence the results of these experiments. The replication also indicates that these results are relatively stable.

\section{EXPERIMENT 3}

The results of Experiments 1 and 2 supported the hypothesis that the degree of visual detail of stimulus materials determines whether the grouping of stimuli into categories (blocking) affects free recall. A further test of this hypothesis was conducted by employing a task manipulation in which the visual detail of stimulus materials varied from the relatively simple to the relatively elaborate. The stimuli were presented in either blocked or unblocked orders, to different groups of subjects. The stimuli employed were objects, color photographs of the objects, line drawings of the objects, and the printed names of the objects. We predicted that as visual detail decreased, there would be a corresponding decrease in free recall and increase in the effect of blocking.

\section{Method}

Subjects. Eighty individuals between the ages of 18 and 44 who had not participated in previous experiments were recruited from introductory psychology classes at the University of Colorado. All 
the subjects possessed a minimum visual acuity of $20 / 40$, corrected or uncorrected.

Materials and Procedure. The name-cards and objects from Experiment 1 were employed in this experiment too. Color photographs and black-and-white line drawings were made of the 40 items, and mounted on $12.7 \times 17.78 \mathrm{~cm}$ white cards. The photographs and drawings formed two new stimulus sets, each consisting of 40 items divided equally among the four categories used in the earlier experiments. For Experiment 3, then, there were four stimulus types: objects, photos, line drawings, and printed names.

The procedure of Experiment 3 was identical to that for the uninformed condition of Experiment 1. The experimenter named each item as it was presented. Naming, which had been left out in Experiment 2 , was reinstated in order to reduce the possibility that subjects confronting the new stimulus types might increase the number of intrusions by using idiosyncratic verbal labels. Because the presence or absence of naming did not affect blocking, its use in Experiment 3 was deemed appropriate.

\section{Results}

Free recall score. The results of Experiment 3 are shown in Table 3 . The effects on free recall of blocking and of stimulus type were significant $[F(1,72)=30.01$, $p<.001, \omega^{2}=.21$, and $F(3,72)=9.52, p<.001$, $\omega^{2}=.18$, respectively]. Blocked stimuli were recalled better than unblocked stimuli, and visually detailed stimuli were recalled better than nondetailed stimuli. The interaction of blocking and stimulus type was also significant $\left[F(3,72)=3.14, p=.030, \omega^{2}=.05\right]$. A Tukey HSD test $(p<.05)$ was used to explore this interaction. No statistically significant blocking effect was found when objects or photographs were used as stimulus materials. Line drawings, however, exhibited a significant blocking effect, as did printed names $(p<.05)$.

ARC score. The effects of blocking and of stimulus type on ARC scores were significant $[F(1,72)=20.717$, $p<.001, \omega^{2}=.18$, and $F(3,72)=3.47, p=.020$, $\left.\omega^{2}=.07\right]$. Blocked stimuli were clustered significantly more than unblocked stimuli, and visually detailed, more memorable stimuli were clustered significantly more than less detailed items. The interaction was not significant.

Table 3

Mean Numbers of Items Recalled and Mean ARC Scores, with Standard Deviations, Experiment 3

\begin{tabular}{|c|c|c|c|c|}
\hline & \multicolumn{2}{|c|}{ Recall Score } & \multicolumn{2}{|c|}{ ARC Score } \\
\hline & $M$ & $S D$ & $M$ & $S D$ \\
\hline \multicolumn{5}{|l|}{ Objects } \\
\hline Blocked & 28.10 & 4.38 & .84 & .22 \\
\hline Unblocked & 26.10 & 3.87 & .50 & .28 \\
\hline \multicolumn{5}{|l|}{ Photos } \\
\hline Blocked & 25.80 & 3.49 & .68 & .27 \\
\hline Unblocked & 22.80 & 3.46 & .50 & .34 \\
\hline \multicolumn{5}{|l|}{ Line Drawings } \\
\hline Blocked & 26.70 & 3.74 & .45 & .32 \\
\hline Unblocked & 20.00 & 5.09 & .32 & .30 \\
\hline \multicolumn{5}{|l|}{ Printed Names } \\
\hline Blocked & 24.60 & 6.08 & .77 & .33 \\
\hline Unblocked & 15.20 & 3.61 & .18 & .33 \\
\hline
\end{tabular}

\section{Discussion}

The findings of Experiment 3 are in agreement with the visual detail hypothesis presented above. Free recall of visually detailed stimuli (objects and photographs) was not affected by blocking. However, free recall for less detailed items (line drawings and printed names) manifested a statistically significant blocking effect.

ARC scores were influenced both by blocking and by stimulus type, but not by the interaction of these factors. These results are in contrast with those of Experiments 1 and 2 , in which stimulus type had no significant effect on ARC scores. A reexamination of the data indicated that the significance of this effect in Experiment 3 was due to a difference between the ARC scores of the unblocked and blocked printed-name conditions that was greater than the corresponding difference in Experiments 1 and 2. Specific analytic comparisons (Tukey B and StudentNewman-Keuls procedures, $p<.05$ ) were made across experiments. These indicated that blocked and unblocked ARC scores varied within the printed name condition across the three experiments: in Experiment 1, this difference was not significant, but in Experiments 2 and 3, significant differences between blocked and unblocked ARC scores within the printed name condition were observed. This probably indicates a greater degree of idiosyncracy in the clustering behavior of subjects than in their free recall, which remained relatively constant in the corresponding conditions across the experiments. If this hypothesis is correct, comparisons of clustering behavior with recall per se could be a source of valuable information about the use of memory strategies.

\section{GENERAL DISCUSSION}

In general, the present findings accord with the existing literature on blocking effects and human memory. In Experiment 1, it was demonstrated that subjects with prior knowledge of categories of stimulus items have a memory advantage over individuals without that knowledge. Additionally, in all three experiments, it was shown that visually detailed stimuli were more memorable than visually less detailed stimuli (e.g., Bevan \& Steger, 1971). However, the observed stimulus dependency of the blocking effect represents a point of departure from earlier work. Statistically significant blocking effects on free recall were observed only under conditions in which the stimuli were printed words, which lack the visual detail of a picture or an actual object, or were visually simple representations (line drawings). No such effect on free recall was observed with visually detailed stimuli, such as objects or photographs of objects.

It is clear from these results that organization by blocking is interactive with the level of visual detail present in stimulus items. It should be pointed out, however, that this does not necessarily imply that the recallability of stimuli in general is interactive with blocking. Visual de- 
tail is one means of increasing recallability. Other memory-enhancing procedures might not show the same interactive patterns with blocking. Further research will be required to determine whether there is a general interaction between the recallability of stimuli and their organization by blocking, or whether this interaction is confined to situations in which recallability is increased by the presence of visual detail.

The robustness of the blocking effect has been treated as an established principle in a variety of studies, including developmental investigations (e.g., Kobasigawa \& Orr, 1973; Kobasigawa \& Wilmhurst, 1973; Moely \& Shapiro, 1971; Yoshimura, Moely, \& Shapiro, 1971). Typically, such studies have not explicitly considered the idea that the blocking effect itself is stimulus-dependent. However, in the present series of experiments, it has been shown that the importance of blocking for real-world memory must be reevaluated with regard to the kinds of stimulus items that are to be remembered.

What remains to be resolved is the relationship between memory for printed words and for non-word stimuli. Visually detailed stimuli are remembered better than nondetailed items (Spoehr \& Lehmkule, 1982). This finding is consistent with depth-of-processing theory (see Craik \& Tulving, 1975): more elaborate stimuli, such as photographs and actual objects, require more processing of detail, which should therefore result in more elaborate encodings associated with enhanced recall. In the present study, the same levels of recall were achieved with visually detailed stimuli when they were blocked by category and when they were not.

Less visually detailed stimuli (such as the line drawings in Experiment 3) require less elaborate encoding, and therefore should be associated with diminished free recall. That is what was found, except when drawings were blocked by category. Drawings blocked by category were recalled at the same level as were blocked or unblocked photographs and objects.

Printed words are not detailed stimuli, because words have less specific visual details than do objects or pictures. Therefore, depth of processing resulting from stimulus elaboration should be relatively minimal with printed word stimuli. However, the remembering of printed word stimuli requires relatively intensive processing. The subject must read the printed word and relate it to his or her fund of knowledge about the item named. It is probable that intensive semantic processing surrounds the encoding of a printed word. We are left, then, with two mutually exclusive possibilities: either the printed word should function like a visually nondetailed item, with minimal depth of processing due to a lack of visual elaboration, or it should function like a highly detailed item, with more depth of processing due to the need to recall and reconstruct semantic associations. In the present study, printed names were the same as line drawings in terms of free recall and the blocking effect.

Yet this finding does not negate the fact that the encoding of the printed word is a processing-intensive activity.
The more likely conclusion is that, with reference to blocked stimulus arrangements, the cognitive processing involved in the recall of printed word stimuli differs in its effect on memory performance from that involved in the recall of visually detailed items. It is hypothesized, then, that depth of processing per se is not sufficient to account for these findings; it appears that there may be different types of processing, with different functional consequences for different types of stimulus materials and memory tasks. Should this hypothesis be confirmed, the understanding of the kinds of processing involved in various cognitive tasks will provide a formidable challenge for future investigation. Paivio's (1971) work on differences between the processing of verbal and imageric information, although criticized and highly controversial (see Anderson \& Bower, 1973; Anderson, 1976), may prove important in this case

In the present study, it has been shown that the level of visual detail, and therefore the ease of recall, of the stimulus items employed in a given study interacts with blocking to affect free recall performance. It has also been indicated strongly that there may be functional differences of nature among the processes involved in the memory of different types of stimuli. The importance of examining cognitive processing under a wide variety of task conditions is underscored.

\section{REFERENCES}

ANDERson, J. R. (1976). Language, memory and thought. Hillsdale NJ: Erlbaum.

ANDERSON, J. R., \& Bower, G. H. (1973). Human associative memory Washington, DC: Winston.

Bevan, W., Steger, J. A. (1971). Free recall and abstractness of stimuli. Science, 172, 597-599.

Buschke, H., \& LAZAR, G. (1973). Cue encoding and recognition in facilitation of recall. Journal of Experimental Psychology, $97,75-78$.

Cofer, C. N., Bruce, D. R., \& Reicher, G. M. (1966). Clustering in free recall as a function of certain methodological variables. Journal of Experimental Psychology, 71, 858-866.

Cole, M., Frankel, F., \& Sharp, D. (1971). Development of free recall learning in children. Developmental Psychology, 4, 109-123.

Craik, F. I. M., Tulving, E. (1975). Depth of processing and the retention of words in episodic memory. Journal of Experimental Psychology: General, 104, 268-294.

Haber, R. N., ERdelyi, M. H. (1967). Emergence and recovery of initially unavailable perceptual material. Journal of Verbal Learning \& Verbal Behavior, 6, 618-628.

HuLTSCH, D. F. (1969). Adult age differences in the organization of free recall. Developmental Psychology, 1, 673-678.

Kobasigawa, A., \& ORR, R. R. (1973). Free recall and retrieval speed of categorized items by kindergarten children. Journal of Experimental Child Psychology, 15, 187-192.

Kobasigawa, A., Wilmhurst, L. A. (1973). Verbal elaboration in young children's free recall learning. Perceptual \& Motor Skills, 36, 1062 .

Kossuth, G. L., Carroll, W. R., Rogers, C. A. (1971). Free recall of words and objects. Developmental Psychology, 4, 480.

Moely, B. E., \& Shapiro, S. I. (1971). Free recall and clustering at four age levels: Effects of learning to leam and presentation method. Developmental Psychology, 4, 490

Nelson, T. O., Metzler, J., ReEd, D. A. (1974). Role of details in the long-term recognition of pictures and verbal descriptions. Joumal of Experimental Psychology, 102, 184-186. 
PAIvio, A. (1969). Mental imagery in associative learning and memory. Psychological Review, 76, 241-263.

PAIvio, A. (1971). Imagery and verbal processes. New York: Holt, Rinehart \& Winston.

Park, D. C., Puglisi, J. T., Smith, A. D. (1986). Memory for pictures: Does an age-related decline exist? Psychology \& Aging, 1, 11-17.

Roenker, D. L., Thompson, C. P., \& Brown, S. C. (1971). Comparison of measures for the estimation of clustering in free recall. Psychological Bulletin, 76, 45-48.

ScoTt, K. G. (1967). Clustering with perceptual and symbolic stimuli in free recall. Joumal of Verbal Learning \& Verbal Behavior, 6, 864-866.

Spoehr, K. T., Lehmkuhle, S. W. (1982). Visual information processing. San Francisco: Freeman.
STRAND, B. (1975). Effects of instructions for category organization on long-term retention. Joumal of Experimental Psychology: Human Leaming \& Memory, 104, 780-786.

TVERSKY, B. (1973). Encoding processes in recognition and recall. Cognitive Psychology, 5, 275-287.

Weber, R., Brown, L., \& WeLDon, J. (1978). Cognitive maps of environmental knowledge and preference in nursing home patients. $E x$ perimental Aging Research, 4, 157-174.

Yoshimura, E. K., Moely, B. E., * Shapiro, S. I. (1971). The influence of age and presentation order upon children's free recall and learning to learn. Psychonomic Science, 23, 261-263.

(Manuscript received August 11, 1987; revision accepted for publication February 11, 1988.) 